Article

\title{
Effect of Thermal Cycle on Microstructure Evolution and Mechanical Properties of Selective Laser Melted Low-Alloy Steel
}

\author{
Xueliang Kang ${ }^{1,2,3}$, Shiyun Dong ${ }^{2, *}$, Hongbin Wang ${ }^{1, *}$, Shixing Yan ${ }^{2}$, Xiaoting Liu ${ }^{2}$ and \\ Huiping $\operatorname{Ren}^{3}$ \\ 1 School of Materials Science and Engineering, Shanghai University, Shanghai 200444, China; \\ kangxueliangyx@163.com \\ 2 National Key Laboratory for Remanufacturing, Army Academy of Armored Forces, Beijing 100072, China; \\ ysxneu@163.com (S.Y.); liuxtbit@126.com (X.L.) \\ 3 Key Laboratory of Integrated Exploitation of Bayan Obo Multi-Metal Resources, Inner Mongolia University \\ of Science and Technology, Baotou 014010, China; renhuiping@sina.com \\ * Correspondence: syd422@sohu.com (S.D.); whb@staff.shu.edu.cn (H.W.)
}

Received: 7 October 2019; Accepted: 28 October 2019; Published: 4 November 2019

check for updates

\begin{abstract}
Low-alloy steel samples were successfully fabricated by selective laser melting (SLM). The evolution of the microstructure and the mechanical properties were investigated with different values of the energy area density (EAD). The results revealed that the initial solidification microstructures of the single tracks with different EADs were all martensite. However, the microstructures of bulk samples under different EADs were not martensite and differed significantly even from one another. When EAD increased from 47 to $142 \mathrm{~J} / \mathrm{mm}^{2}$, the mixed lower bainite and martensite austenite microstructure changed to granular bainite; further, the morphology of bainite ferrite gradually changed from lath to multilateral. Moreover, with the increase of EAD, the grain size was remarkably reduced because of the increasing austenitizing periods and temperature during thermal cycling. The average grain size was $1.56 \mu \mathrm{m}, 3.98 \mu \mathrm{m}$, and $6.31 \mu \mathrm{m}$ with EADs of $142 \mathrm{~J} / \mathrm{mm}^{2}, 71 \mathrm{~J} / \mathrm{mm}^{2}$, and $47 \mathrm{~J} / \mathrm{mm}^{2}$, respectively. Yield strength and tensile strength of the SLM low-alloy steel increased with the increase in EAD; these values were significantly more than those of the alloys prepared by traditional methods. The microstructure of the SLM low-alloy steel samples is not uniform, and the inhomogeneity becomes more significant as EAD decreases. Simultaneously, when EAD decreases, the fracture mechanism changes from ductile to a mixture of ductile and brittle fracture; this is in contrast to the samples prepared by traditional methods. This study also found a stress concentration mechanism around large pores during plastic deformation that resulted in a brittle fracture. This indicates that large-sized pores significantly degrade the mechanical properties of the specimens.
\end{abstract}

Keywords: selective laser melting; thermal cycle; microstructure evolution; mechanical property; low-alloy steel

\section{Introduction}

Selective laser melting (SLM) is a manufacturing technique rapidly developing worldwide because of its ability to deliver metal parts with high density, good surface quality, and high mechanical properties [1-3]. During the SLM process, the computer-aided design (CAD) model of the part is computationally sliced in thin layers. According to pre-set parameters (such as laser power, scanning speed, scanning path, etc.), the pre-laid powders are melted and then solidified by moving the laser beam. After printing one layer, the process is repeated until the SLM component is completed. The SLM 
technology has obvious advantages over traditional methods in manufacturing complex structural components, and for this reason it is increasingly being used in industry.

Recently, the SLM technology has been widely used to fabricate metal components, including parts of titanium alloys [4-6], copper alloys [7,8], aluminum alloys [9], nickel-based alloys [10], etc. Several studies reported on the preparation of ferrous alloys by SLM, among which many focused on 316L steel [11-13]. For instance, Tomasz Kurzynowski et al. [14] studied the correlation between SLM pre-set parameters and the final properties of 316L stainless steel, including its microstructure. They found that the laser energy density and the scanning strategy strongly affect the austenite cellular substructure and the amount of ferrite, as well as the texture. Almangour et al. [15] mainly focused on the microstructural arrangement and size of TiC nanoparticles under different processing parameters, and on the grain sizes and tribological performances of SLM-processed nanocomposite parts. Di et al. [16] studied the effect of laser speed on the grain structure development of 316L stainless steel, including grain growth mode and their final density, and on its mechanical properties.

The matrix phase of 316L steel is austenite, which does not change under the effect of thermal cycling. However, few studies investigated the effect of thermal cycling on the microstructure of 316L steel. The microstructure of low-alloy steel is very sensitive to the influence of heat. After solidification, austenite, pearlite, upper, granular and lower bainite, and martensite may form under different cooling conditions. These microstructures also undergo phase transformation when heated. Tempered martensite, recrystallized ferrite, tempered bainite, tempered toxote troostite, and tempered sorbite may form at different heating temperatures. The different microstructures have a great impact on the mechanical properties of the components.

Several studies are available on low-alloy steel. Yue et al. [17] studied the evolution of bainite and the mechanical properties of direct laser deposited $12 \mathrm{CrNi} 2$ alloy steel for different laser power. They found that the microstructures changed under different processing parameters, though they did not unravel their formation mechanism. Mingwei et al. [18] investigated the microstructural evolution of $24 \mathrm{CrNiMo}$ steel for different SLM power and found that heat accumulation occurs during SLM. However, the authors did not analyze the microstructure formation mechanism. Zuo et al. [19] studied the microstructure evolution of $24 \mathrm{CrNiMoY}$ alloy steel parts in SLM. They found different microstructures in at least one sample, and while they probed thermal cycling in the SLM process, they did not unravel its effect on the microstructure evolution.

A SLM part is fabricated track by track and layer by layer. As a consequence, the temperature field changes dramatically during the process $[20,21]$. Heat input and heat accumulation can have a significant impact on the preformed microstructure, so the final microstructure of SLM-formed low-alloy steel can be very complex. The thermal cycling process is different for the specimens formed under different SLM parameters, and so is the phase transformation. Thus, different microstructures are finally obtained. At present, limited research has focused on the processing parameters, the effect of thermal cycle, the microstructure evolution, and the mechanical properties of low-alloy steel in SLM. In this paper, we discuss in detail the effect of energy area density (EAD), as a substitution to scanning speed, on these properties.

\section{Experimental Materials and Methods}

\subsection{Powder Material}

The low-alloy steel powder was prepared by vacuum induction melting gas atomization method. The average diameter of the powder grains was below $50 \mu \mathrm{m}$ and their shapes were nearly spherical. A representative image of the powder morphology is shown in Figure 1. The chemical compositions are listed in Table 1. 


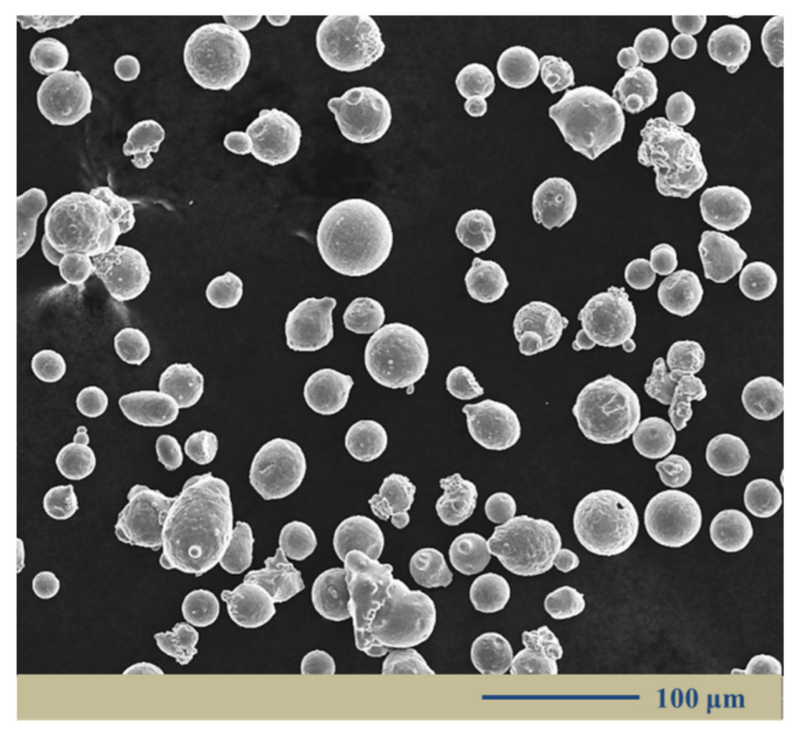

Figure 1. Scanning electron microscopy (SEM) image of low-alloy steel powder.

Table 1. Chemical compositions of the low-alloy steel powder used in this work (wt \%).

\begin{tabular}{ccccccc}
\hline Element & $\mathbf{C}$ & $\mathbf{M n}$ & $\mathbf{N i}$ & $\mathbf{M o}$ & $\mathbf{Y}$ & $\mathbf{F e}$ \\
\hline Content & $0.15-0.25$ & 0.6 & 1.0 & 0.5 & $0.01-0.05$ & Bal. \\
\hline
\end{tabular}

\subsection{Microstructural Characterization and Mechanical Test}

The as-fabricated samples were microstructurally characterized at their yz cross section. The samples were grounded and polished following standard procedures and were etched in alcohol nitrate solution ( $5 \mathrm{~mL} \mathrm{HNO}_{3}+95 \mathrm{~mL} \mathrm{C}_{2} \mathrm{H}_{5} \mathrm{OH}$ ) for about $10 \mathrm{~s}$ prior to microstructural characterization. This was carried out using a PMG3 optical microscope (OM) and a Nova NanoSEM50 field emission scanning electron microscope (FESEM) at $30 \mathrm{kV}$. The grain morphology and size were obtained by electron backscatter diffraction (EBSD) characterization. The samples were electropolished $(8 \mathrm{~mL}$ $\mathrm{HClO}_{4}+92 \mathrm{~mL} \mathrm{C}_{2} \mathrm{H}_{5} \mathrm{OH},-15{ }^{\circ} \mathrm{C}, 15 \mathrm{~s}$ ) prior to EBSD analysis. We characterized the substructures of the samples by transmission electron microscopy (TEM) and measured their phase transition temperature using a thermal expansion tester with a heating rate of $10^{\circ} \mathrm{C} / \mathrm{s}$ and a cooling rate of $5{ }^{\circ} \mathrm{C} / \mathrm{s}$. The tensile test was carried out at room temperature on a CMT5105 testing machine at a stretching speed of $0.6 \mathrm{~mm} / \mathrm{min}$. We used scanning electron microscopy (SEM) to characterize the tensile fracture surfaces. The tensile plate specimens were cut along the $x$ direction as depicted in Figure 2, and their dimensions are reproduced in Figure 3.

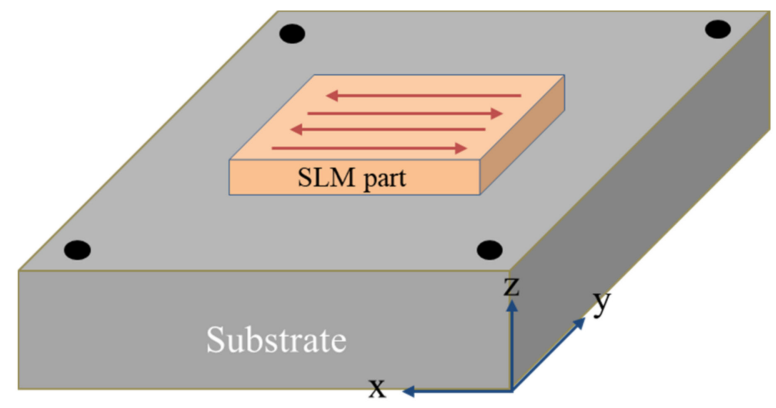

Figure 2. Schematic illustration of a selective laser melting (SLM)-fabricated low-alloy steel part. 


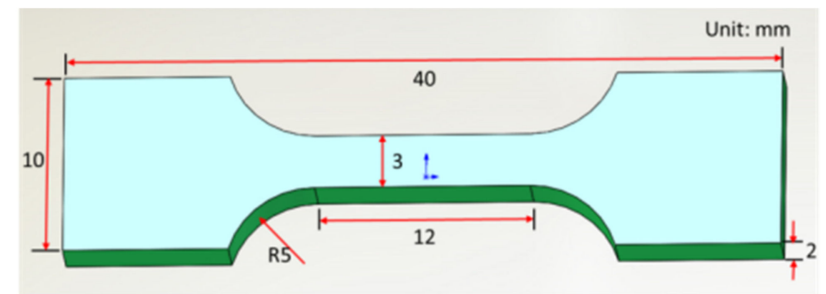

Figure 3. Dimensions of the tensile plate specimens.

\subsection{SLM Process}

The SLM samples were prepared in a Renishaw AM400 system. The powder was dried at $90{ }^{\circ} \mathrm{C}$ for $2 \mathrm{~h}$ prior to its usage and the oxygen content in the fabrication cabin was kept below $200 \mathrm{ppm}$. The diameter of the laser spot was $70 \mu \mathrm{m}$. A zigzag scanning strategy was used (Figure 2) with the overlap ratio between adjacent tracks set at 45\%. Detailed working parameters are listed in Table 2.

Table 2. Working parameters of the SLM process.

\begin{tabular}{cccccc}
\hline $\begin{array}{c}\text { Layer Thickness } \\
(\boldsymbol{\mu m})\end{array}$ & $\begin{array}{c}\text { Laser Power } \\
(\mathbf{W})\end{array}$ & $\begin{array}{c}\text { Point Distance } \\
(\boldsymbol{\mu} \mathbf{m})\end{array}$ & $\begin{array}{c}\text { Exposure Time } \\
(\boldsymbol{\mu} \mathbf{s})\end{array}$ & $\begin{array}{c}\text { Scan Speed } \\
(\mathbf{m m} / \mathbf{s})\end{array}$ & $\begin{array}{c}\text { EAD } \\
\left(\mathbf{J} / \mathbf{m m}^{2}\right)\end{array}$ \\
\hline 50 & 200 & 10 & 1000 & 10 & 284 \\
50 & 200 & 10 & 500 & 20 & 142 \\
50 & 200 & 10 & 250 & 40 & 71 \\
50 & 200 & 10 & 166 & 60 & 47 \\
50 & 200 & 10 & 125 & 80 & 36 \\
50 & 200 & 10 & 100 & 100 & 29 \\
\hline
\end{tabular}

EAD: energy area density.

Several sample batches were prepared, using different scanning speeds. It should be noted that the laser was pulsed and the laser spot scanning speed $(\mathrm{v})$ was determined by point distance $(\mathrm{d})$ and exposure time $(t)$ through the relation [22,23]:

$$
\mathrm{v}=\frac{\mathrm{d}}{\mathrm{t}}
$$

where $d$ represents the distance between adjacent positions and $t$ represents the residence time of the laser spot in one position. The laser scanning mode and the point distance are schematically represented in Figure 4.

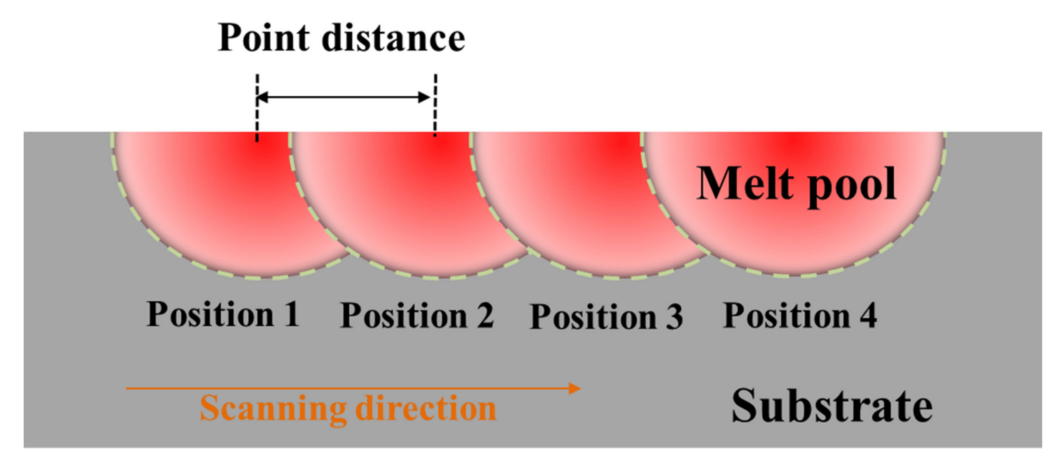

Figure 4. Schematic illustration of point distance of the pulsed laser.

The energy area density (EAD) is used to measure the input laser energy and is defined as [3]:

$$
\mathrm{EAD}=\frac{\mathrm{P}}{\mathrm{V} * \mathrm{D}}
$$


where $P$ is the laser power $(W), v$ is the scan speed $(\mathrm{mm} / \mathrm{s})$, and $D$ is the laser spot diameter $(\mathrm{mm})$.

We used the finite element method to study the evolution of the temperature field. We experimentally measured the thermal physical properties of the fabricated low-alloy steel below $900{ }^{\circ} \mathrm{C}$ and used the dynamic simulation software JMATPRO to calculate them above this temperature, due to the testing limitations. The thermal physical properties evolution is shown in Table 3.

Table 3. Thermal properties of SLM fabricated low-alloy steel at different temperatures.

\begin{tabular}{cccc}
\hline $\begin{array}{c}\text { Temperature } \\
\left({ }^{\circ} \mathbf{C}\right)\end{array}$ & $\begin{array}{c}\text { Density } \\
\left(\mathbf{K g} / \mathbf{m}^{\mathbf{3}}\right)\end{array}$ & $\begin{array}{c}\text { Thermal Conductivity } \\
\mathbf{( W / m ~ K )}\end{array}$ & $\begin{array}{c}\text { Specific Heat } \\
\mathbf{( J / k g ~ K )}\end{array}$ \\
\hline 25 & 7841 & 34.9 & 447 \\
100 & 7820 & 33.4 & 450 \\
300 & 7818 & 33.6 & 521 \\
500 & 7827 & 30.4 & 615 \\
700 & 7717 & 27.3 & 880 \\
900 & 7609 & 27.0 & 609 \\
1100 & 7504 & 29.5 & 639 \\
1300 & 7399 & 31.9 & 673 \\
1450 & 7347 & 33.2 & 696 \\
1470 & 7193 & 33.3 & 1071 \\
1510 & 7071 & 33.5 & 11,507 \\
\hline
\end{tabular}

\section{Results and Discussion}

\subsection{Formability Characterization}

The SLM block formability is a key factor for its mechanical properties [24,25]. The formability can be controlled by optimizing the process parameters, and EAD is a crucial one. Figure 5 shows the evolution of the SLM parts relative density with an increasing EAD. To measure the relative density, we used the Archimedes principle. As seen from Figure 5, the density evolution is not monotonic. For an EAD in the $47-142 \mathrm{~J} / \mathrm{mm}^{2}$ range, the relative density of the samples reaches up to $99 \%$, so that the metallographic section of the sample displays a reduced porosity. When EAD lays below $50 \mathrm{~J} / \mathrm{mm}^{2}$ or exceeds $150 \mathrm{~J} / \mathrm{mm}^{2}$, the relative density decreases due to the macro-defects seen from the reported cross sections.

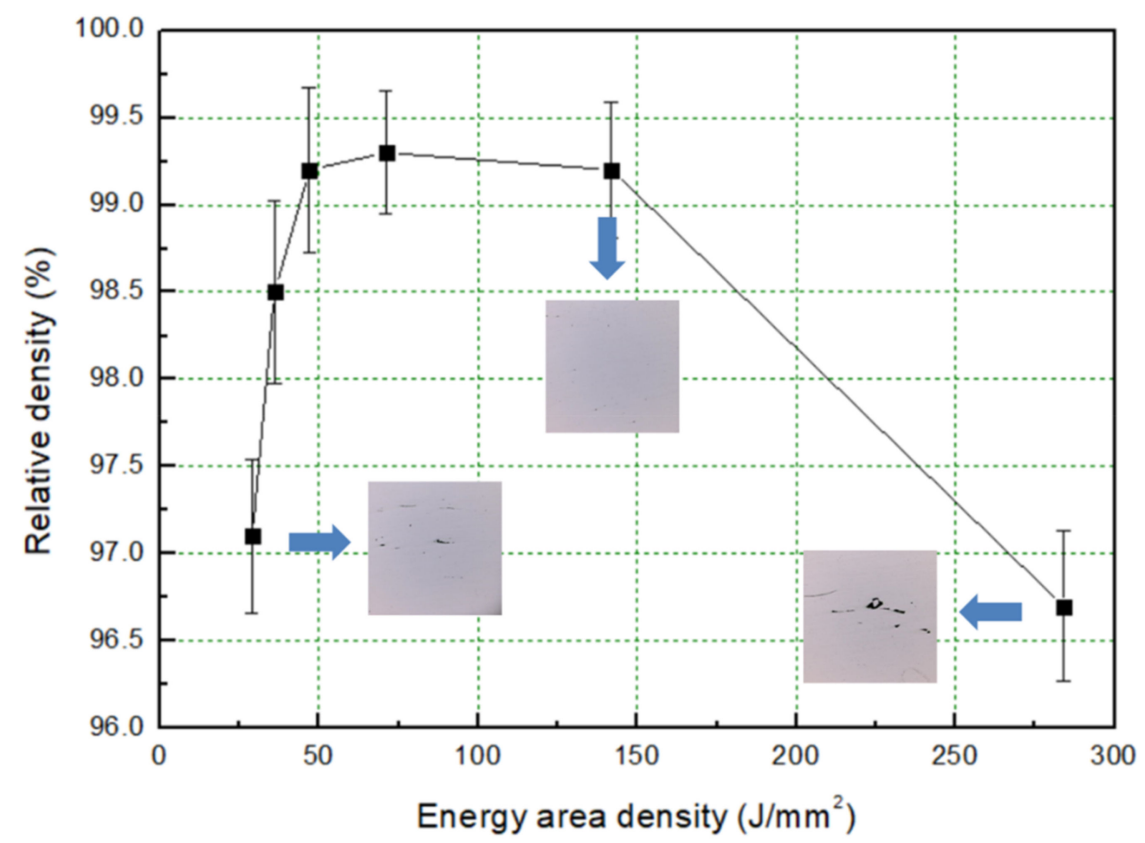

Figure 5. Evolution of the relative density of SLM low-alloy steel with EAD. 


\subsection{Microstructural Characterization}

Due to rapid cooling and solidification, the SLM samples have a non-equilibrium microstructure [26], and as in all alloys with a solid phase, this will change during the thermal cycle. Thus, a complex microstructure results in these SLM-fabricated alloys $[27,28]$. Figure 6 shows the cross-section morphology and the corresponding microstructure of the SLM single tracks at different EADs. The microstructures of the three samples are martensite, as seen from Figure $6 \mathrm{~d}-\mathrm{f}$. This is because the single-track microstructure is only imposed by the cooling rate of the SLM molten pool. The cooling rate $\Delta \mathrm{T} / \Delta \mathrm{t}$ can be calculated by [29]:

$$
\frac{\Delta \mathrm{T}}{\Delta \mathrm{t}}=\frac{\alpha_{\lambda} \mathrm{Q} \sqrt{\mathrm{v}}}{d_{m}^{2} \sqrt{2 \rho c k d}}
$$

where $\alpha_{\lambda}$ is the absorptivity at laser wavelength $\lambda, Q$ is the laser power, $v$ is the scanning speed, $\rho$ is the metal density, $\mathrm{c}$ is the specific heat, $\mathrm{k}$ is the thermal conductivity, and $d_{m}$ is the diameter of the melt pool. According to Equation (3), the cooling rate of the molten pool can reach values of $10^{5}-10^{6}{ }^{\circ} \mathrm{C} / \mathrm{s}$ during the solidification process. From the continuous cooling transition (CCT) curve of SLM low-alloy steel shown in Figure 7, it can be seen that when the cooling rate of the molten pool is greater than $100^{\circ} \mathrm{C} / \mathrm{s}$, the microstructure at room temperature mainly consists of martensite. Since the cooling rate of the molten pool during the SLM process is far greater than $100{ }^{\circ} \mathrm{C} / \mathrm{s}$, the single track microstructure is the same after cooling regardless of the EAD, mainly consisting of martensite as shown in Figure $6 \mathrm{~d}-\mathrm{f}$.

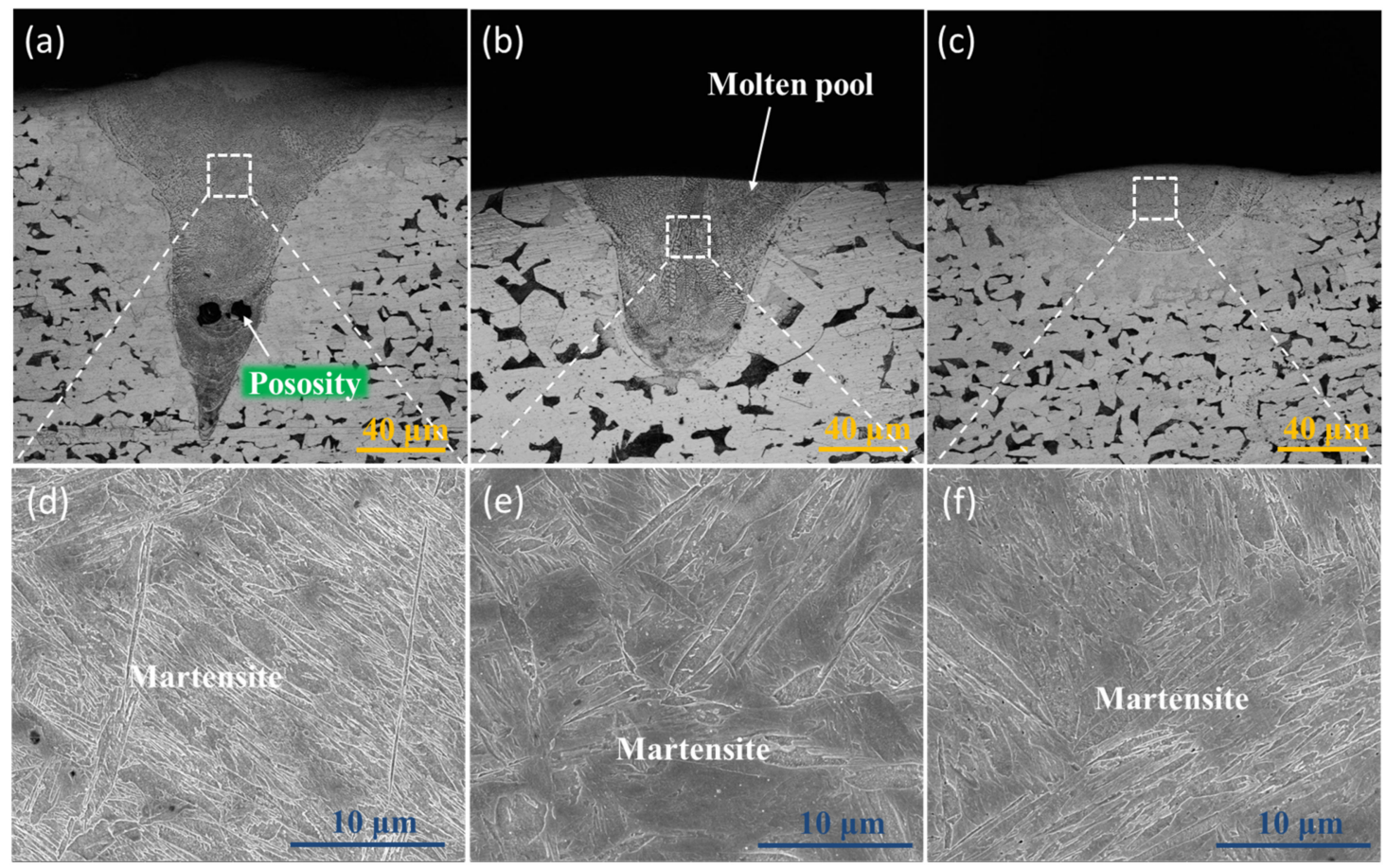

Figure 6. Molten pool morphologies and corresponding microstructural SEM images of SLM low-alloy steel samples grown with different EADs: $(\mathbf{a}, \mathbf{d})$ EAD $=284 \mathrm{~J} / \mathrm{mm}^{2} ;(\mathbf{b}, \mathbf{e})$ EAD $=71 \mathrm{~J} / \mathrm{mm}^{2} ;(\mathbf{c}, \mathbf{f})$ EAD = $29 \mathrm{~J} / \mathrm{mm}^{2}$. 


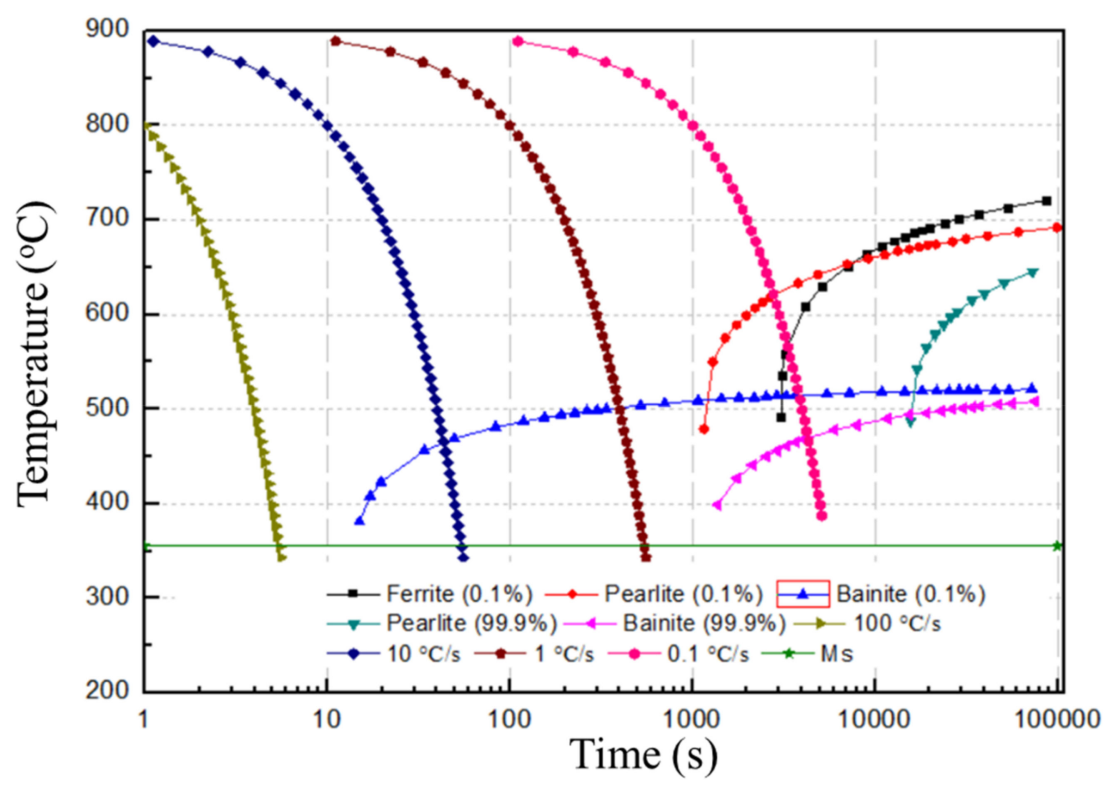

Figure 7. Continuous cooling transition (CCT) curve of low-alloy steel.

However, the bulk samples microstructure is no longer martensite, and samples manufactured with different EADs have different microstructures, as shown in Figure 8. At a high EAD $\left(142 \mathrm{~J} / \mathrm{mm}^{2}\right)$, the microstructure is granular bainite (GB) composed of bainitic ferrite $(\mathrm{BF})$ and martensite-austenite (M-A) constituents. As EAD reaches $71 \mathrm{~J} / \mathrm{mm}^{2}$, the GB transforms into lower bainite (LB), which significantly increases in content as EAD further decreases to $47 \mathrm{~J} / \mathrm{mm}^{2}$.
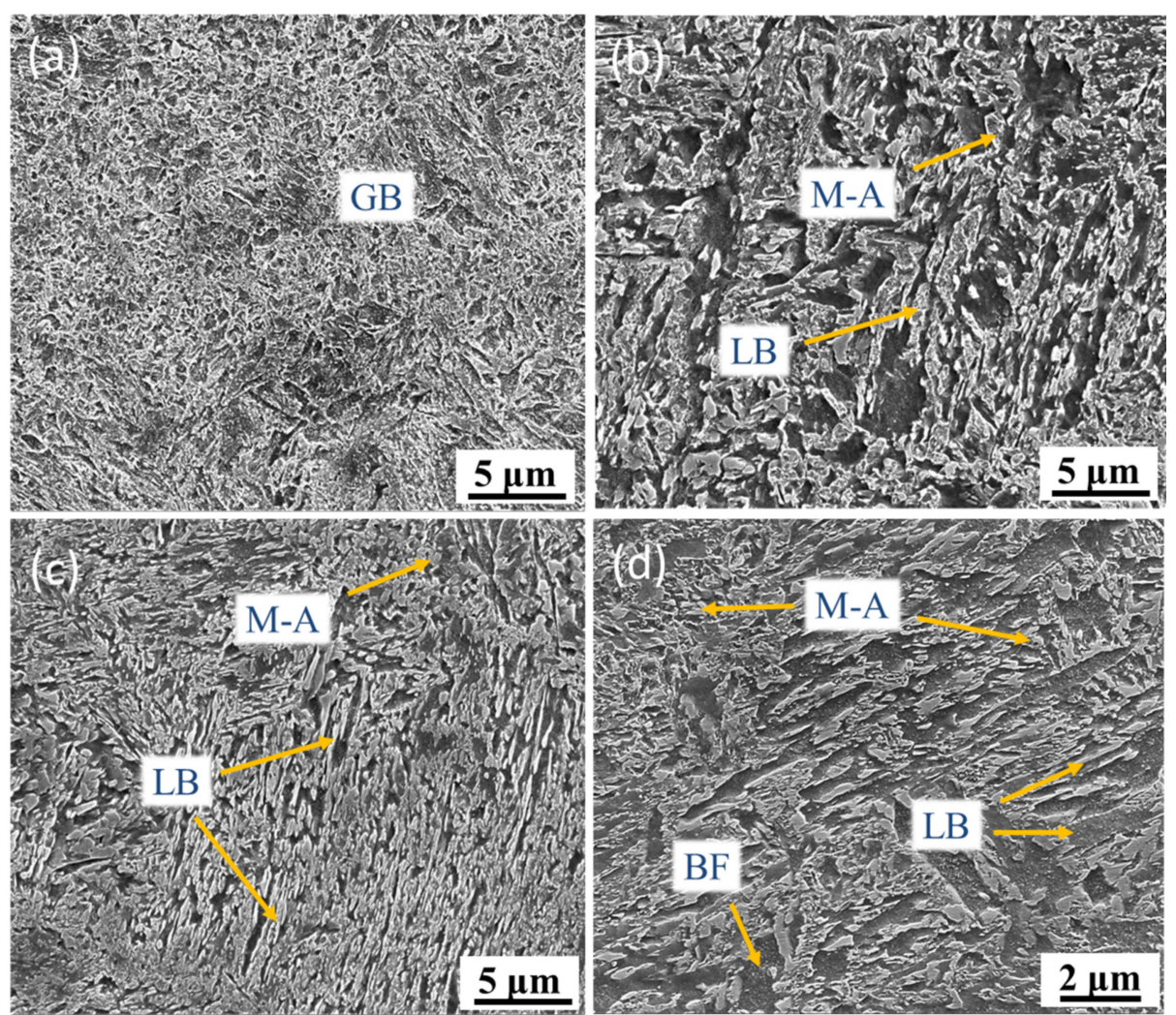

Figure 8. Microstructures of SLM low-alloy steel samples grown with different EADs: (a) EAD = $142 \mathrm{~J} / \mathrm{mm}^{2}$; (b) EAD $=71 \mathrm{~J} / \mathrm{mm}^{2}$; (c) EAD $=47 \mathrm{~J} / \mathrm{mm}^{2}$; and (d) zoomed-in image of (b). GB: granular bainite; M-A: martensite-austenite; LB: lower bainite; BF: bainitic ferrite. 
According to the equilibrium phase diagram of low-alloy steel, the microstructure at room temperature is mainly composed of ferrite and cementite. Austenite is also present under rapid solidification conditions. The phase content and distribution was studied by EBSD, as shown in Figure 9. As seen, retained austenite is found in all samples, and its content increases with the decrease of EAD. The presence of retained austenite is caused by the high cooling rate, and its content increases with it.

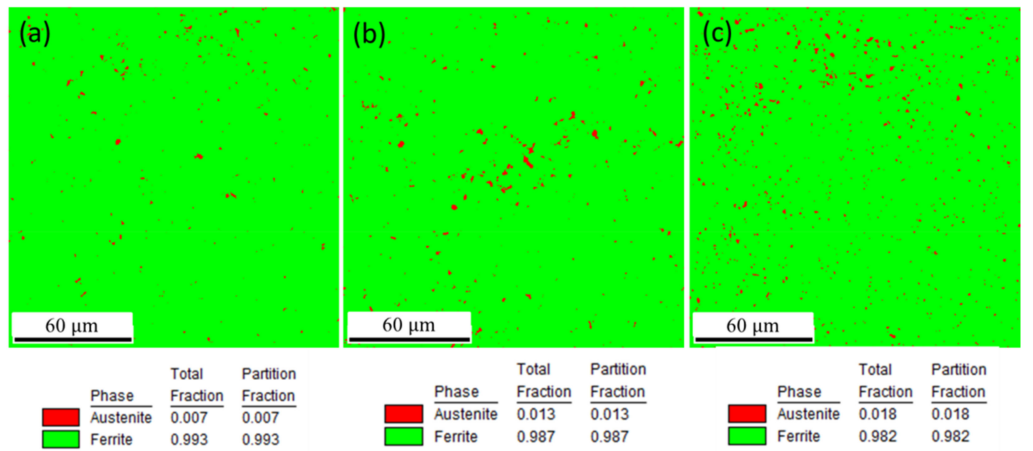

Figure 9. Phase composition of SLM low-alloy steel samples grown with different EADs: (a) EAD = $142 \mathrm{~J} / \mathrm{mm}^{2} ;(\mathbf{b}) \mathrm{EAD}=71 \mathrm{~J} / \mathrm{mm}^{2}$; and (c) EAD $=47 \mathrm{~J} / \mathrm{mm}^{2}$.

We used TEM to characterize the samples' substructure further, and the results are reported in Figure 10. As can be seen, at a low EAD $\left(47 \mathrm{~J} / \mathrm{mm}^{2}\right)$, the morphology of ferrite is that of parallel laths of about $100 \mathrm{~nm}$ in width, with retained austenite (RA) in between. With the increase of EAD $\left(71 \mathrm{~J} / \mathrm{mm}^{2}\right)$, the lath-like ferrite was refined to a width of about $30 \mathrm{~nm}$ only. In addition, complex substructures of polygonal BF are formed. When EAD reaches $142 \mathrm{~J} / \mathrm{mm}^{2}$, the sample microstructure consists of mainly polygonal BF and fine M-A. From the substructure characterization of the samples, it can be concluded that the microstructure average size is reduced by increasing EAD.
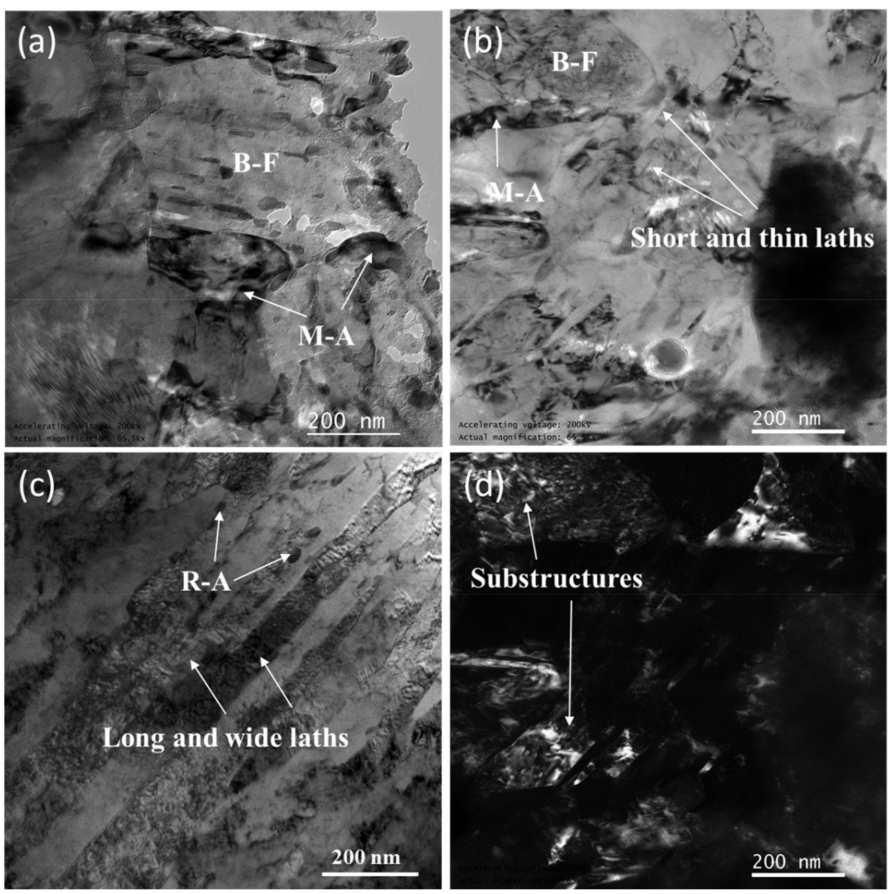

Figure 10. TEM morphology of SLM low-alloy steel samples grown with different EADs: (a) EAD $=142 \mathrm{~J} / \mathrm{mm}^{2} ;(\mathbf{b}) \mathrm{EAD}=71 \mathrm{~J} / \mathrm{mm}^{2} ;$ (c) EAD $=47 \mathrm{~J} / \mathrm{mm}^{2}$; and (d) dark field image of (b). R-A: retained austenite. 
In order to determine the grain size of SLM low-alloy steel samples at different EADs, we carried out EBSD analysis. According to the inverse pole figures (IPFs) of Figure 11, the differences in grain size among the samples is significant, with average values of $1.56 \mu \mathrm{m}, 3.98 \mu \mathrm{m}$, and $6.31 \mu \mathrm{m}$ at EADs of $142 \mathrm{~J} / \mathrm{mm}^{2}, 71 \mathrm{~J} / \mathrm{mm}^{2}$, and $47 \mathrm{~J} / \mathrm{mm}^{2}$, respectively. As expected from the grain size decreasing with the increase of EAD, the morphology of the grains changed from lath-like to multilateral.

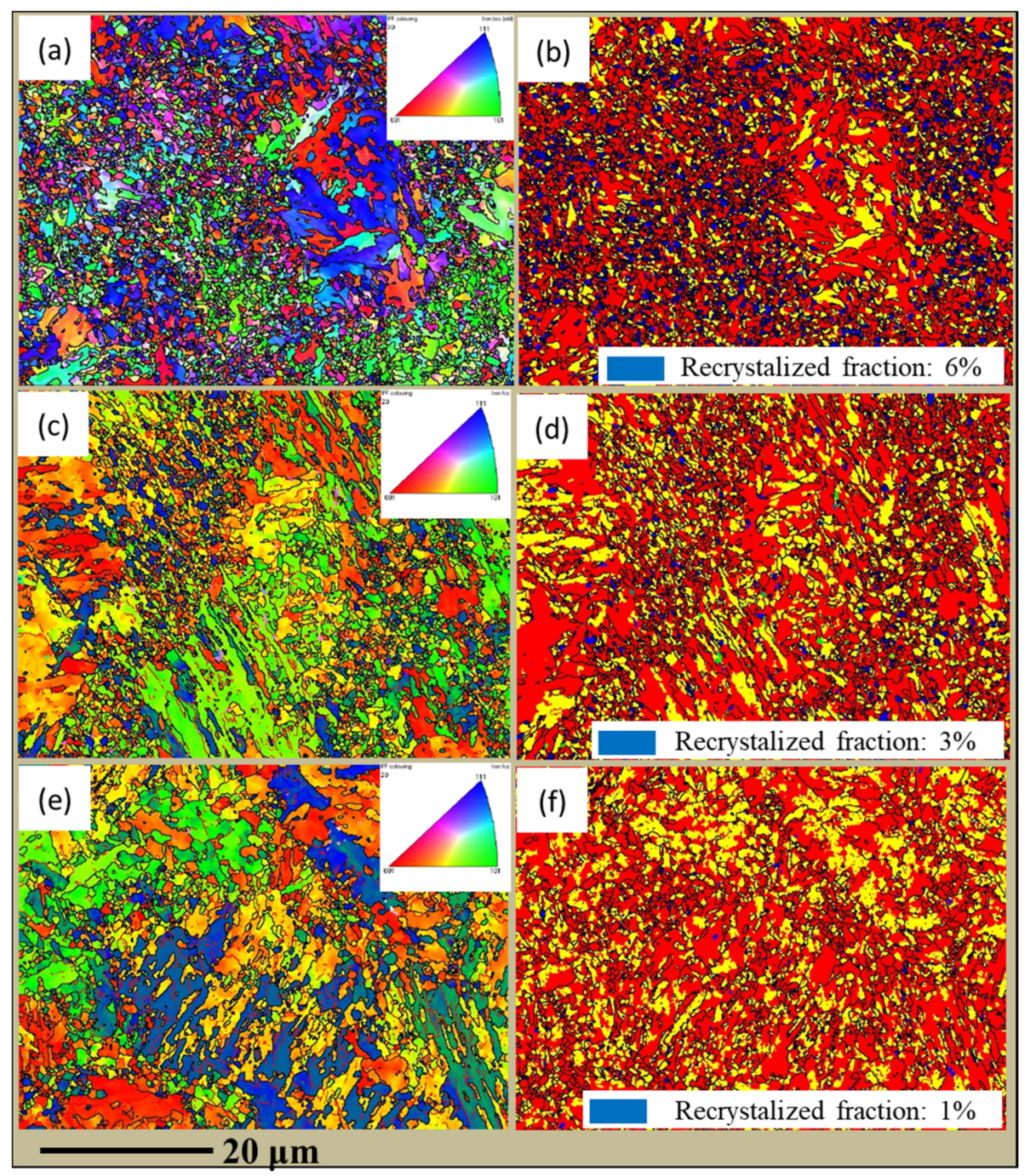

Figure 11. Inverse pole figures and recrystallized grains distribution of SLM low-alloy steel samples grown with different EADs: $(\mathbf{a}, \mathbf{b})$ EAD $=142 \mathrm{~J} / \mathrm{mm}^{2}$; (c,d) EAD $=71 \mathrm{~J} / \mathrm{mm}^{2} ;(\mathbf{e}, \mathbf{f})$ EAD $=47 \mathrm{~J} / \mathrm{mm}^{2}$.

As discussed above, the as-solidified molten pool microstructure does not vary with EAD, and the difference in bulk sample microstructure and grain size is mainly due to the thermal cycle, which causes martensite to undergo different phase transformations. The martensite starting temperature (Ms) in the low-alloy steel was measured at $362{ }^{\circ} \mathrm{C}$ (Figure 12), which is very close to the value of $382.5^{\circ} \mathrm{C}$ obtained from the equation [30]:

$$
\begin{gathered}
M_{S}\left({ }^{\circ} \mathrm{C}\right)=539-423(\% \mathrm{C})-30.4(\mathrm{Mn})-17.7(\% \mathrm{Ni})-12.1(\% \mathrm{Cr}) \\
-7.5(\% \mathrm{Mo})
\end{gathered}
$$




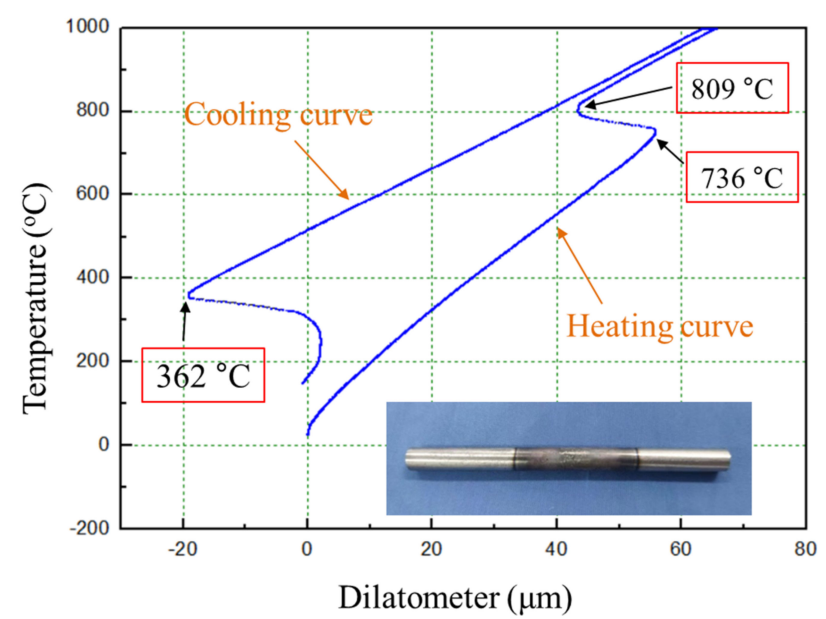

Figure 12. Thermal expansion curve during heating and cooling of the low-alloy steel.

Similarly, the temperatures $\mathrm{AC}_{1}$ and $\mathrm{AC}_{3}$ were measured to be $736{ }^{\circ} \mathrm{C}$ and $809{ }^{\circ} \mathrm{C}$, respectively. However, the bainite start temperature (Bs) cannot be determined from the measured curve of Figure 12 , though its value can be calculated to be about $520^{\circ} \mathrm{C}$ by:

$$
\begin{gathered}
B_{S}\left({ }^{\circ} \mathrm{C}\right)=830-270(\% \mathrm{C})-90(\mathrm{Mn})-37(\% \mathrm{Ni})-70(\% \mathrm{Cr}) \\
-83(\% \mathrm{Mo})
\end{gathered}
$$

To study the effect of thermal cycling on the microstructure evolution, we simulated a temperature field of the block sample (four layers, eight tracks per layer) depicted in Figure 13a. Figure 13b-d shows the influence of the heat from the fourth layer on the temperature at a fixed position (middle point of track three, layer three, labeled A) for different EAD. It can be seen that point A undergoes several heating and cooling cycles during the fabrication of layer four, with significantly different heating temperature and time. The specific parameters of the thermal cycle process are reported in Table 4.

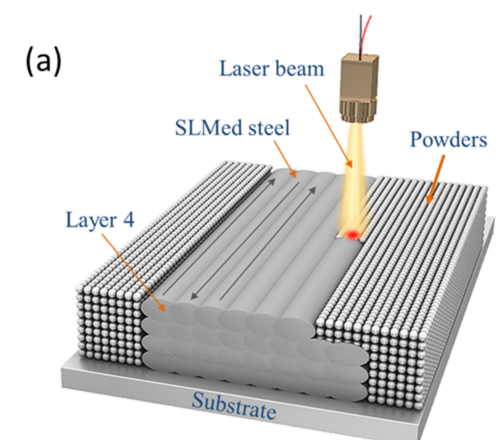

(c)

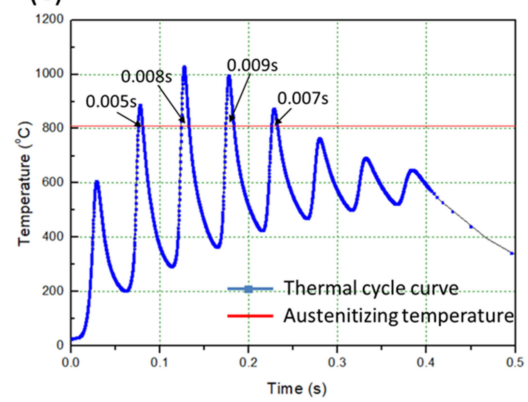

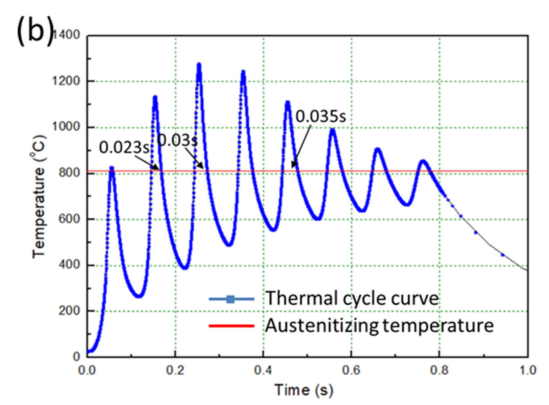

(d)

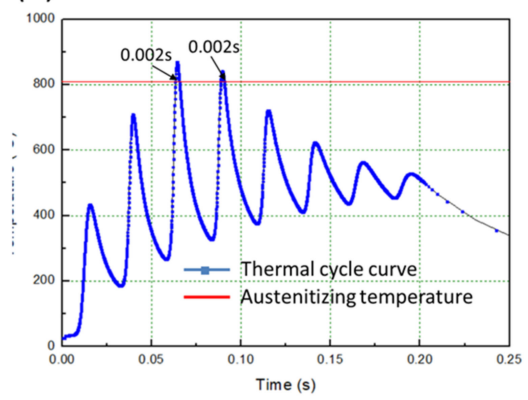

Figure 13. (a) Schematic diagram of SLM formation of low-alloy steel; (b-d) thermal cycle curves in the middle point of track three, layer three, at different EADs: (b) EAD $=142 \mathrm{~J} / \mathrm{mm}^{2}$; (c) $\mathrm{EAD}=71 \mathrm{~J} / \mathrm{mm}^{2}$; (d) $\mathrm{EAD}=47 \mathrm{~J} / \mathrm{mm}^{2}$. 
Table 4. Specific parameters of the thermal cycle process.

\begin{tabular}{ccccc}
\hline $\begin{array}{c}\text { EAD } \\
\left(\mathrm{J} / \mathbf{m m}^{2}\right)\end{array}$ & $\begin{array}{c}\text { Austenitizing } \\
\text { Times }\end{array}$ & $\begin{array}{c}\text { Maximum Heating } \\
\text { Temperature }\left({ }^{\circ} \mathbf{C}\right)\end{array}$ & $\begin{array}{c}\text { Heating Rate } \\
\left({ }^{\circ} \mathbf{C} / \mathbf{s}\right)\end{array}$ & $\begin{array}{c}\text { Austenitizing } \\
\text { Time (s) }\end{array}$ \\
\hline 142 & 7 & 1279 & $2.7 \times 10^{4}$ & 0.03 \\
71 & 4 & 1029 & $5.2 \times 10^{4}$ & 0.008 \\
47 & 2 & 868 & $10 \times 10^{4}$ & 0.002 \\
\hline
\end{tabular}

As the temperature raises to $\mathrm{AC}_{3}$, the martensite entirely transforms into austenite. Austenitization is a continuous process of nucleation and growth. The nucleation rate I can be calculated by

$$
\mathrm{I}=\mathrm{C} \times \exp \left(-\frac{\mathrm{Q}+\mathrm{W}}{\mathrm{kT}}\right)
$$

where $\mathrm{C}$ is a constant, $\mathrm{Q}$ is the diffusion activation energy, $\mathrm{W}$ is the critical nucleation energy of the crystal, $\mathrm{k}$ is the Boltzmann constant, and $\mathrm{T}$ is the temperature. According to Equation (6), a higher temperature enhances the nucleation rate and consequently the grain size decreases. As can be seen from Table 4, the maximum heating temperature at point $\mathrm{A}$ increases with $\mathrm{EAD}$, resulting in a higher nucleation rate and a finer grain size. As evidenced in Figure $11 \mathrm{~b}, \mathrm{~d}, \mathrm{f}$, our results consistently support this behavior for the nucleation rate (recrystallized fraction) of austenite.

Furthermore, it is known that multiple austenitizing processes can contribute to grain refinement [31,32]. As seen from Table 4, the microstructure was austenitized 2, 4, and 7 times for increasing EAD, so an increasingly refined grain size is expected.

In addition to the size, the morphology of the grains also changes. Austenite grains nucleate at boundaries of martensitic laths during the austenitizing process. The nucleation and growth of the grains require a long time because they depend on the components' diffusion. If the austenitizing process is too short, the components diffusion is not uniform and only limited austenite grains form, thus an untransformed lath-like structure is retained during subsequent cooling. If the components are provided with sufficient diffusion times, the multilateral austenite grains completely replace the lath-like structure and retain their morphology upon cooling. The process is schematically represented in Figure 14.

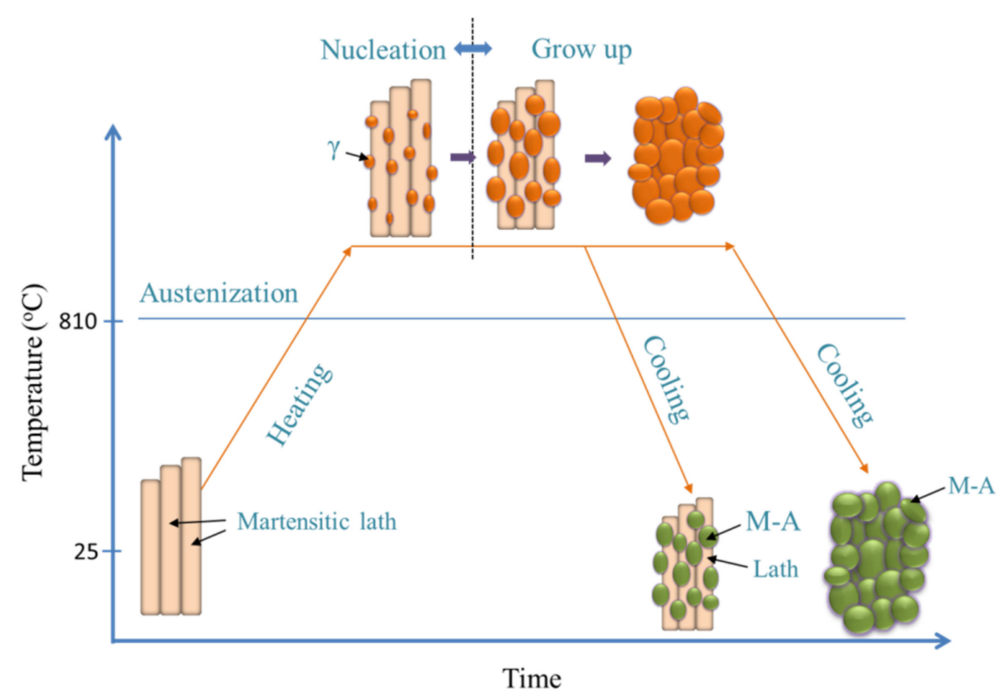

Figure 14. Schematic illustration of the microstructure evolution process.

As seen from Table 4, the sample fabricated at an EAD of $142 \mathrm{~J} / \mathrm{mm}^{2}$ experienced a high temperature and a quite long heating time. Therefore, the components diffusion is enhanced, and the grains of the 
high-EAD samples are expected to be mostly multilateral. Instead, the grains of the low-EAD sample mostly display a lath-like morphology.

\subsection{Tensile Tests Analysis}

The yield stress (YS), the ultimate tensile stress (UTS), and the elongation (EL) of the samples are listed in Table 5. Here, the mechanical properties of the low-alloy steel prepared by traditional methods (labeled "Sample A") that we tested are also listed. For EADs between 47 and $142 \mathrm{~J} / \mathrm{mm}^{2}$, the yield strength and ultimate tensile strength increases with the EAD of the SLM low-alloy steels. However, the behavior of elongation with EAD is not obvious. It is worth mentioning that YS and UTS of the SLM low-alloy steel prepared in this paper can reach $1256 \mathrm{MPa}$ and $1428 \mathrm{MPa}$, respectively, far exceeding those of the alloys prepared by traditional methods and those reported in literature for alloy steel. However, in samples with EAD of $36 \mathrm{~J} / \mathrm{mm}^{2}$, the mechanical properties are significantly reduced.

Table 5. Room temperature tensile properties of SLM low-alloy steel.

\begin{tabular}{cccc}
\hline Sample Description & YS (MPa) & UTS (MPa) & EL (\%) \\
\hline EAD $=142 \mathrm{~J} / \mathrm{mm}^{2}$ & 1256 & 1428 & 15.9 \\
$\mathrm{EAD}=71 \mathrm{~J} / \mathrm{mm}^{2}$ & 1233 & 1385 & 16.2 \\
$\mathrm{EAD}=47 \mathrm{~J} / \mathrm{mm}^{2}$ & 1205 & 1357 & 16.3 \\
$\mathrm{EAD}=36 \mathrm{~J} / \mathrm{mm}^{2}$ & 982 & 765 & 5.8 \\
Sample A & 1080 & 1199 & 16.5 \\
Wei [18] & 956 & 1146 & 14.9 \\
Zhouyue [17] & 704.2 & 774.6 & 7.1 \\
Tingting Guan [33] & 702 & 901 & 15.2 \\
\hline
\end{tabular}

YS: yield stress; UTS: ultimate tensile stress; EL: elongation.

The presence of many substructures in the microstructure is an important reason for the outstanding mechanical properties of alloy steels, as shown in Figure 10. These substructures can effectively hinder the movement of dislocations. Furthermore, crack propagation can be prevented by the diffuse distribution of M-A in the matrix, thus improving the steel strength.

The grain size is also a key factor in the strength of the specimen. The effect of grain size on yield strength can be calculated through the Hall-Petch relation [33]

$$
\sigma_{y}=\sigma_{0}+k d_{g}^{-0.5}
$$

where $\sigma_{y}$ is the yield strength, $d_{g}$ is the average grain size, $\sigma_{0}$ and $k$ are material constants.

As discussed, the average grain size is $1.56 \mu \mathrm{m}, 3.98 \mu \mathrm{m}$, and $6.31 \mu \mathrm{m}$ for samples with EADs of $142 \mathrm{~J} / \mathrm{mm}^{2}, 71 \mathrm{~J} / \mathrm{mm}^{2}$, and $47 \mathrm{~J} / \mathrm{mm}^{2}$, respectively, thus much smaller than that prepared by traditional methods. According to Equation (7), refined grains increase the yield strength and improve the plasticity of the sample.

\subsection{Fracture Analysis}

The SEM fracture images of SLM low-alloy steel samples grown with different EADs are shown in Figure 15. For the three samples, the fracture mechanism was ductile. Overall, when EAD is highest $\left(E A D=142 \mathrm{~J} / \mathrm{mm}^{2}\right)$, the dimples are smaller because the grains are finer. Some smaller pores are seen in the fracture of Figure 15b. The pore size is nearly equal that of the dimples, and little influence on the surrounding dimples can be derived. Such micro-size pores can hardly be avoided in SLM processes. However, we can infer that their effect on the tensile properties of the samples is minimal. 


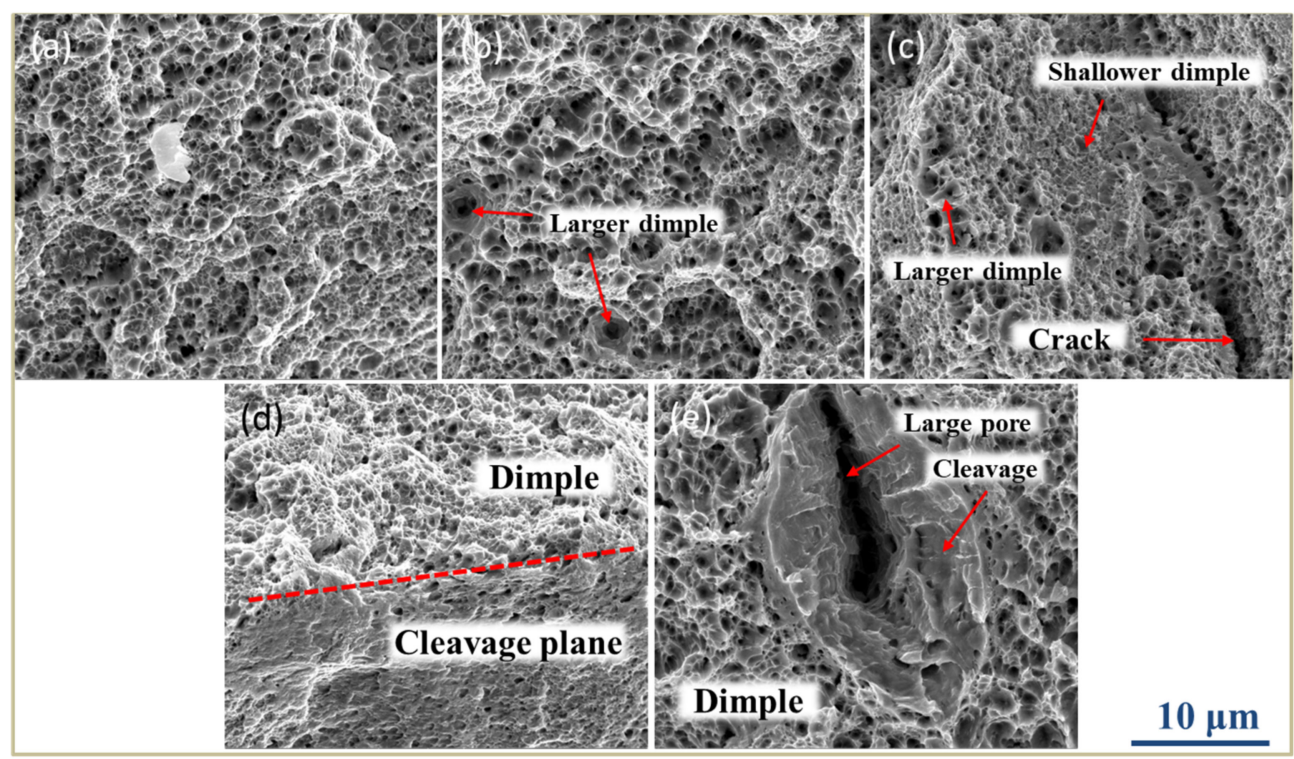

Figure 15. SEM images of fractures in SLM low-alloy steel samples grown with different EADs: (a) EAD $=142 \mathrm{~J} / \mathrm{mm}^{2} ;(\mathbf{b}) \mathrm{EAD}=71 \mathrm{~J} / \mathrm{mm}^{2} ;(\mathbf{c}, \mathbf{d}) \mathrm{EAD}=47 \mathrm{~J} / \mathrm{mm}^{2}$, and $(\mathbf{e}) \mathrm{EAD}=36 \mathrm{~J} / \mathrm{mm}^{2}$.

The most important feature of the SLM low-alloy steel samples is the uneven fracture mechanism. One of the consequences of the non-uniform fracture morphologies is that different fracture properties appear in the cross section images. As shown in Figure 15c, different types of fracture properties are found in one area. Furthermore, as shown in Figure 15d, the dimples corresponding to ductile fracture and the smooth cleavage surfaces corresponding to brittle fracture occur simultaneously. Such a peculiar phenomenon is caused by the inhomogeneity of the microstructure. As seen from Figure 11, the grain size in each sample is inhomogeneous, and the resistance to deformation differs for differently sized grains, thus a non-uniform fracture forms upon deformation. Another kind of non-uniform fracture morphology is caused by large pores in the facture as those shown in Figure 15e. As seen, the pore size is far greater than that of the dimple. The pore changes its shape during deformation, and because it breaks the matrix continuity, stress concentration occurs around it, leading to brittle fracture. As a consequence, the presence of large pores can seriously affect the tensile properties of the specimens.

\section{Conclusions}

(1) Thermal cycling has a decisive effect on the microstructure evolution of SLM low-alloy steel samples. The initial solidification microstructure of the molten pool is martensite. With the increase of EAD, martensite gradually transforms into a mixed microstructure of bainite and martensite-austenite, and into granular bainite in turn. Bainite ferrite gradually changes from lath to a multilateral structure under the action of subsequent thermal cycles.

(2) Thermal cycling also has a crucial effect on the grain size of the SLM low-alloy steel samples. The average grain size is $1.56 \mu \mathrm{m}, 3.98 \mu \mathrm{m}$, and $6.31 \mu \mathrm{m}$ at EADs of $142 \mathrm{~J} / \mathrm{mm}^{2}, 71 \mathrm{~J} / \mathrm{mm}^{2}$, and $47 \mathrm{~J} / \mathrm{mm}^{2}$, respectively. Thus, with the increase of EAD, the grain size is remarkably reduced due to the increase of austenitizing cycles and temperature.

(3) With the increase of EAD, yield strength and tensile strength of the low-alloy steel increase and their values far exceed those of the alloys prepared by traditional methods and those of alloy steels reported in literature. The change of elongation with EAD is not obvious.

(4) The grain size and microstructure are uneven in SLM low-alloy steel samples. The inhomogeneity becomes more significant with the decrease of EAD. When EAD is below $47 \mathrm{~J} / \mathrm{mm}^{2}$, the fracture mechanism of the SLM low-alloy steel sample changes from ductile to a mixture of ductile and brittle fracture. 
Author Contributions: Data curation, S.Y., X.L. and H.R.; Funding acquisition, S.D. and H.W.; Investigation, X.K.

Funding: This research was funded by National Key R\&D Program of China (2016YFB1100205) and National Natural Science Foundation of China (51705532).

Conflicts of Interest: The authors declare no conflict of interest.

\section{References}

1. Zhang, L.C.; Attar, H.; Calin, M.; Eckert, J. Review on manufacture by selective laser melting and properties of titanium based materials for biomedical applications. Mater. Process. Rep. 2016, 31, 66-76. [CrossRef]

2. Yan, L.; Yuan, Y.; Ouyang, L.; Li, H.; Mirzasadeghi, A.; Li, L. Improved mechanical properties of the new Ti-15Ta- $x$ Zr alloys fabricated by selective laser melting for biomedical application. J. Alloy. Compd. 2016, 688, 156-162. [CrossRef]

3. Di, W.; Yimeng, W.; Shibiao, W.; Hui, L.; Yongqiang, Y.; Shicai, F. Customized a Ti6Al4V Bone Plate for Complex Pelvic Fracture by Selective Laser Melting. Materials 2017, 10, 35.

4. Grigoriev, A.; Polozov, I.; Sufiiarov, V.; Popovich, A. In-situ synthesis of Ti 2 AlNb-based intermetallic alloy by selective laser melting. J. Alloy. Compd. 2017, 704, 434-442. [CrossRef]

5. Wei, K.; Wang, Z.; Zeng, X. Preliminary investigation on selective laser melting of Ti-5Al-2.5Sn $\alpha$-Ti alloy: From single tracks to bulk 3D components. J. Mater. Process. Technol. 2017, 244, 73-85. [CrossRef]

6. Gu, D.; Hagedorn, Y.C.; Meiners, W.; Meng, G.; Poprawe, R. Densification behavior, microstructure evolution, and wear performance of selective laser melting processed commercially pure titanium. Acta Mater. 2012, 60, 3849-3860. [CrossRef]

7. Mao, Z.; Zhang, D.Z.; Wei, P.; Zhang, K. Manufacturing Feasibility and Forming Properties of Cu-4Sn in Selective Laser Melting. Materials 2017, 10, 333. [CrossRef]

8. Zhang, G.; Chen, C.; Wang, X.; Wang, P.; Zhang, X.; Gan, X. Additive manufacturing of fine-structured copper alloy by selective laser melting of pre-alloyed $\mathrm{Cu}-15 \mathrm{Ni}-8 \mathrm{Sn}$ powder. Int. J. Adv. Manuf. Technol. 2018, 96, 1-8. [CrossRef]

9. Kimura, T.; Nakamoto, T. Microstructures and mechanical properties of A356 (AlSi7Mg0.3) aluminum alloy fabricated by selective laser melting. Mater. Des. 2015, 89, 1294-1301. [CrossRef]

10. Saedi, S.; Turabi, A.S.; Andani, M.T.; Haberland, C.; Karaca, H.; Elahinia, M. The influence of heat treatment on the thermomechanical response of Ni-rich NiTi alloys manufactured by selective laser melting. J. Alloy. Compd. 2016, 677, 204-210. [CrossRef]

11. Yan, C.; Hao, L.; Hussein, A.; Young, P.; Raymont, D. Advanced lightweight 3161 stainless steel cellular lattice structures fabricated via selective laser melting. Mater. Des. 2014, 55, 533-541. [CrossRef]

12. Almangour, B.; Grzesiak, D.; Yang, J.M. Rapid fabrication of bulk-form TiB2/316L stainless steel nanocomposites with novel reinforcement architecture and improved performance by selective laser melting. J. Alloy. Compd. 2016, 680, 480-493. [CrossRef]

13. Shang, Y.; Yuan, Y.; Li, D.; Li, Y.; Chen, J. Effects of scanning speed on in vitro biocompatibility of 316L stainless steel parts elaborated by selective laser melting. Int. J. Adv. Manuf. Technol. 2017, 92, 1-7. [CrossRef]

14. Kurzynowski, T.; Gruber, K.; Stopyra, W.; Kuźnicka, B.; Chlebus, E. Correlation between process parameters, microstructure and properties of 316L stainless steel processed by selective laser melting. Mater. Sci. Eng. A 2018, 718, 64-73. [CrossRef]

15. Almangour, B.; Grzesiak, D.; Cheng, J.; Ertas, Y. Thermal behavior of the molten pool, microstructural evolution, and tribological performance during selective laser melting of TiC/316L stainless steel nanocomposites: Experimental and simulation methods. J. Mater. Process. Technol. 2018, 257, 288-301. [CrossRef]

16. $\mathrm{Di}, \mathrm{W}$. Investigation of crystal growth mechanism during selective laser melting and mechanical property characterization of 316L stainless steel parts. Mater. Des. 2016, 100, 291-299.

17. Zhou, Y.; Chen, S.; Chen, X.; Cui, T.; Liang, J.; Liu, C. The evolution of bainite and mechanical properties of direct laser deposition $12 \mathrm{CrNi} 2$ alloy steel at different laser power. Mater. Sci. Eng. A 2019, 742, 150-161. [CrossRef]

18. Mingwei, W.; Suiyuan, C.; Lianyun, X.; Jing, L.; Changsheng, L. Selective laser melting of 24CrNiMo steel for brake disc: Fabrication efficiency, microstructure evolution, and properties. Opt. Laser Technol. 2018, 107, 99-109. 
19. Zuo, P.; Chen, S.; Wei, M.; Zhou, L.; Liang, J.; Liu, C.; Wang, M. Microstructure evolution of 24CrNiMoY alloy steel parts by high power selective laser melting. J. Manuf. Process. 2019, 44, 28-37. [CrossRef]

20. Lianfeng, W.; Xiaohui, J.; Yihong, Z.; Xiaogang, Z.; Jing, S.; Biao, Y. An approach to predict the residual stress and distortion during the selective laser melting of AlSi10Mg parts. Int. J. Adv. Manuf. Technol. 2018, 97, 3535-3546.

21. Yan, J.J.; Zheng, D.L.; Li, H.X.; Jia, X.; Yan, M. Selective laser melting of H13: Microstructure and residual stress. J. Mater. Sci. 2017, 52, 12476-12485. [CrossRef]

22. Li, Z.; Li, B.-Q.; Bai, P.; Liu, B.; Wang, Y. Research on the Thermal Behaviour of a Selectively Laser Melted Aluminium Alloy: Simulation and Experiment. Materials 2018, 11, 1172. [CrossRef] [PubMed]

23. Karimi, P.; Raza, T.; Andersson, J.; Svensson, L.E. Influence of laser exposure time and point distance on 75- $\mu \mathrm{m}$-thick layer of selective laser melted Alloy 718. Int. J. Adv. Manuf. Technol. 2017, 94, 2199-2207. [CrossRef]

24. Ye, D.; Hong, G.S.; Zhang, Y.; Zhu, K.; Fuh, J.Y.H. Defect detection in selective laser melting technology by acoustic signals with deep belief networks. Int. J. Adv. Manuf. Technol. 2018, 96, 2791-2801. [CrossRef]

25. Akita, M.; Uematsu, Y.; Kakiuchi, T.; Nakajima, M.; Kawaguchi, R. Defect-dominated fatigue behavior in type 630 stainless steel fabricated by selective laser melting. Mater. Sci. Eng. A 2016, 666, 19-26. [CrossRef]

26. Das, M.; Balla, V.K.; Basu, D.; Bose, S.; Bandyopadhyay, A. Laser processing of SiC-particle-reinforced coating on titanium. Scr. Mater. 2010, 63, 438-441. [CrossRef]

27. Xuezhi, S.; Shuyuan, M.; Changmeng, L.; Cheng, C.; Qianru, W.; Xianping, C. Performance of High Layer Thickness in Selective Laser Melting of Ti6Al4V. Materials 2016, 9, 975.

28. Ran, X.; Liu, D.; Li, A.; Wang, H.; Tang, H.; Cheng, X. Microstructure characterization and mechanical behavior of laser additive manufactured ultrahigh-strength AerMet100 steel. Mater. Sci. Eng. A 2016, 663, 69-77. [CrossRef]

29. Almangour, B.; Grzesiak, D.; Borkar, T.; Yang, J.M. Densification behavior, microstructural evolution, and mechanical properties of TiC/316L nanocomposites fabricated by selective laser melting. Mater. Des. 2017, 138, 119-128. [CrossRef]

30. Leslie, W.C. The Physical Metallurgy of Steels; Hempisphere Pub. Corp: New York, NY, USA, 1981.

31. Cooper, K.P.; Jones, H.N. Phase transformation-induced grain refinement in rapidly solidified ultra-high-carbon steels. Metall. Mater. Trans. A 2002, 33, 2789-2799. [CrossRef]

32. Grange, R.A. The rapid heat treatment of steel. Metall. Trans. 1971, 2, 65-78. [CrossRef]

33. Guan, T.; Chen, S.; Chen, X.; Liang, J.; Liu, C.; Wang, M. Effect of laser incident energy on microstructures and mechanical properties of 12CrNi2Y alloy steel by direct laser deposition. J. Mater. Sci. Technol. 2018. [CrossRef]

(C) 2019 by the authors. Licensee MDPI, Basel, Switzerland. This article is an open access article distributed under the terms and conditions of the Creative Commons Attribution (CC BY) license (http://creativecommons.org/licenses/by/4.0/). 